УДК 621.396.2.019.4 : 621.391 .254

\title{
МЕТОД АДАПТИВНОГО ДЕКОДИРОВАНИЯ ПРИ ПЕРЕДАЧЕ ИНФОРМАЦИИ В УСЛОВИЯХ ВОЗДЕЙСТВИЯ ПРЕДНАМЕРЕННЫХ ПОМЕХ
}

\author{
ЗАЙЦЕВ С. В., КАЗИМИР В. В. \\ Черниговский национальный технологический университет, \\ Украина, Чернигов, 14027, ул. Шевченко, 95
}

\begin{abstract}
Аннотация. Предложен метод повышения достоверности передачи информации в беспроводных сетях, функционирующих в условиях воздействия преднамеренных помех. Метод основан на дополнительном использовании показателя неопределенности при принятии решений в турбо декодере и адаптивном регулировании итераций декодирования турбо кода в условиях нестационарности канала передачи. В процессе адаптивного регулирования итераций декодирования турбо кода изменяется количество итераций декодирования для каждого пакета данных, основываясь на динамическом расчете значения показателя неопределенности. Результаты имитационного моделирования показали, что с увеличением отношения сигнал-помеха количество итераций декодирования уменьшается, а достоверность передачи информации при этом увеличивается
\end{abstract}

Ключевые слова: турбо код; неопределенность; моделирование

\section{ВВЕДЕНИЕ}

В современных телекоммуникационных системах для повышения достоверности передачи информации используются помехоустойчивые коды: блочные коды, коды БЧХ, Рида-Соломона, Рида-Маллера, каскадные коды, сверточные коды, турбо коды (ТК) и др. Наиболее эффективными среди них являются ТК, которые по энергетической эффективности уступают теоретическому пределу Шеннона 0,5 дБ [1].

На сегодняшний день, благодаря повышенной энергетической эффективности, ТК применяются в системах мобильной связи третьего поколения 3G (cdma2000, cdma2000 1xEV-DO, cdma2000 1xEV-DV, UMTS), системе LTE, в системах связи CCSDS для передачи телеметрической информации от космических аппаратов, в системах спутникового цифрового телевидения DVB-RCS [2-7] и др. Однако указанные системы не предусматривают возможность их эффективного функционирования в условиях воздействия преднамеренных помех, создаваемых, в том числе, средствами радиоэлектронного подавления [5]. Подобного рода помехи могут существенно влиять на достоверность передачи информации [8].

\section{АНАЛИЗ ИССЛЕДОВАНИЙ И ПУБЛИКАЦИЙ}

Известно несколько подходов к повышению достоверности систем с ТК. Подход $[9,10]$ заключается в оптимизации перемежителя в структуре ТК. В этом случае энергетический выигрыш происходит при отношении сигнал-помеха в области «порога ошибок» ТК. Другой подход [11] заключается в применении дополнительных бит по завершению кодирования блока данных с целью принудительного перевода решетчатой диаграммы рекурсивно- 